\title{
QTc interval-dependent body posture in pediatrics
}

\author{
Björn Reynisson, Gustaf Tanghöj and Estelle Naumburg ${ }^{*}$
}

\begin{abstract}
Background: Syncope is a common and often benign disorder presenting at the pediatric emergency department. Long-QT syndrome may be presented with syncope, ventricular arrhythmias or sudden death and is vital to exclude as an underlying cause in children presented with syncope. Few studies have assessed QTC in relation to body posture in children. In this study, we assessed the QTc interval while laying down and during active standing in children with known long-QT syndrome compared to healthy controls.

Methods: Children aged 1-18years with long-QT syndrome $(N=17)$ matched to two healthy controls $(N=34)$ were included in this case-control study. The ECG standing was performed immediately after the ECG in the supine position. The QTc interval and QTc-difference by changing the body position were calculated.

Results: All children with long-QT syndrome were treated with propranolol. QTC was prolonged among long-QT syndrome children while lying down and when standing up, compared to controls. A prolongation of QTC appeared when standing up for both cases and controls. There was no significant difference in QTc increase between the groups. A QTc over 440 ms was observed among four cases lying down and in eight cases while standing, but not in any of the controls. The standing test with a cut-off of $440 \mathrm{~ms}$ showed a sensitivity of $47 \%$ and a specificity of $100 \%$ for case-status in our study.

Conclusion: QTc measured on ECG when rapidly rising up is prolonged in both healthy and LQTS children. More importantly, it prolongs more in children with LQTS and increases in pathological levels.
\end{abstract}

Keywords: Child, Electrocardiography, Long QT-syndrome, Pediatrics, QTc, Standing test, Syncope

\section{Background}

Syncope is a common condition in the pediatric population [1]. The underlying cause of syncope is often benign and often explained by orthostatic intolerance or vasovagal reactions $[2,3]$. However, some life-threatening diseases may present as syncope during childhood $[2,4,5]$.

Long QT syndrome (LQTS) is an uncommon genetic cardiac electrophysiological disorder in which altered ion channels within the myocytes cause prolonged repolarization [6]. This alteration may induce Torsades de Pointes (TdP) and lethal ventricular tachyarrythmias [7]. LQTS often presents as QT-prolongation and T-wave abnormalities on an electrocardiogram (ECG) [6, 8]. Congenital LQTS is an autosomal dominant hereditary disease caused by mutations in one or several known genes that regulate the function of ion channels of the

\footnotetext{
* Correspondence: naumburg@umu.se

Institution of Clinical Science, Pediatrics, Umeå University, Umeå, Sweden
}

myocytes [9]. The most common types found in genotyped cases are mutations associated with LQT1, LQT2 and LQT3 $[6,10]$. Genetic testing is available and a routine procedure in known families and is used in the evaluation of malignant syncope [11-13]. According to national guidelines, prophylactic treatment with propranolol is recommended for all children with LQTS in Sweden [14].

The QT-interval in ECG is suggested to be adjusted to heart rhythm, QT-corrected time (QTc). In children 115 years of age, a QTc $>440 \mathrm{~ms}$ is considered to be the borderline upper limit of the QTc interval, while QTc > $460 \mathrm{~ms}$ is considered prolonged according to the national guidelines [14]. Over $25 \%$ of genetically evident LQTS have a normal ECG, and $10-15 \%$ of the general adult population has a borderline QTc $[7,15]$. Thus, ECG combined with medical and hereditary history is included in the evaluation of children at risk [16, 17].

(c) The Author(s). 2020 Open Access This article is distributed under the terms of the Creative Commons Attribution 4.0 International License (http://creativecommons.org/licenses/by/4.0/), which permits unrestricted use, distribution, and 
Genetic testing is not first in line in patients with syncope admitted to the pediatric department. Lifethreatening cardiac causes must be ruled out by ECG, exercise testing (EST) and/or 24-h ECG [18]. EST and 24-h ECG are costly or not possible in younger children and/or are often associated with a long waiting list. There is a need for an easily available method when assessing malignant syncope in children [19].

Postural changes are known to increase heart rate, heart rate variability and syncope $[20,21]$. A significant change in QT-interval and QTc interval when standing is seen in adults with known LQTS compared to controls [22, 23]. An increase in QTc-interval among healthy children when standing has been shown in a few studies, indicating the need for more research [24-26]. No studies have compared QTc alterations in children with LQTS compared to healthy controls.

We hypothesized that a standing test could be valuable in the evaluation of QTc in children. Furthermore, we hypothesized that QTc measured while standing is prolonged in children with LQTS compared to otherwise healthy children.

\section{Methods}

\section{Materials}

This pilot case-control study included children between 1 and 18 years of age with genetically diagnosed LQTS attending the Pediatric Cardiology department at Östersund Hospital, Sweden. Two healthy cardiac controls matched by age and gender were randomly selected from the pediatric department while attending the clinic for other reasons.

\section{Method}

A standard 12-lead ECG was conducted in a rested supine body position and followed by an ECG immediately after standing up. The children rested in the supine position for as long as needed for a reliable ECG. The ECG were conducted in a supine position and immediately followed by active standing. Information on age, height, weight, other medical conditions, medication, blood pressure, history of syncope or family members with known LQTS was retrieved for cases as well as controls. Drugs were stratified into four groups: 1) beta-blockers, 2) drugs that can cause QT prolongation or induce TdP, 3 ) other medications and 4) occasional medications. The "List of drugs to be avoided by congenital LQTS patients" available at www.crediblemeds.org was used for classification.

\section{ECG measures}

The QT interval was manually measured predominantly in lead II or using other leads when the quality of lead II was low. The QT-interval was measured in milliseconds (ms) from the beginning of the QRS-complex to the end of the $\mathrm{T}$-wave using the tangent method to locate the end of the T-wave [27]. Bazett's formula was used for QTc calculations [28]. QTc was measured for cases and controls in supine follow by a standing body position. Three medical doctors calculated QTc intervals individually, and two of these doctors were blinded with regard to case and control status as well as to body position. The mean QTc value was calculated between these separate measurements. A standing test using a cut-off value of $440 \mathrm{~ms}$ to define risk for LQTS was performed. Specificity and sensitivity were calculated for the standing test to identify LQTS cases among cases and controls.

\section{Statistical analysis}

Interobserver variability of ECG measurements was calculated using Cornbach's analysis. All data are presented as the mean (SD), median (range) or percentage (\%) depending on the type and distribution of the data. Continuous data were primarily tested for normality using the Shapiro-Wilks test. Student's t-test (paired two-sided) was used for parametrically distributed variables within groups, One-way ANOVA between the groups, Repeated measures ANOVA for QTc changes and Person's $\mathrm{X}^{2}$ or Fisher's exact test for categorical data according to fit, with $p<0.05$ considered to be significant. All statistical analyses were performed using SPSS, version 25.

\section{Results}

\section{Study-group demographics}

Overall, 20 children were identified with LQTS at the pediatric cardiac departments. Two children were excluded due to incapacity to follow instructions due to young age and one declined participation, leaving 17 children to be included in the study (Fig. 1). Two cases were randomly matched to each case, including a total of 51 children in the study (17 cases and 34 controls).

The mean age for cases was 9.0 years ( \pm 4.2 years), and for controls, 9,4 years ( \pm 4.2 years) and $76 \%$ of study participants were less than 12 years of age. There was no difference between cases and controls with regard to gender distribution, age, height, weight, history of syncope, other diseases or noncardiac medications (Table 1). Treatment with beta-blockers, a lower blood pressure and a heredity for LQTS was more common among cases compared to controls (Table 1).

\section{QTc interval and body position}

Interobserver analysis of QTc measurements showed an interclass correlation level of $0.855(p<0.001)$ for QTc in the supine position and $0.884(p<0.001)$ for QTc in the standing position. 


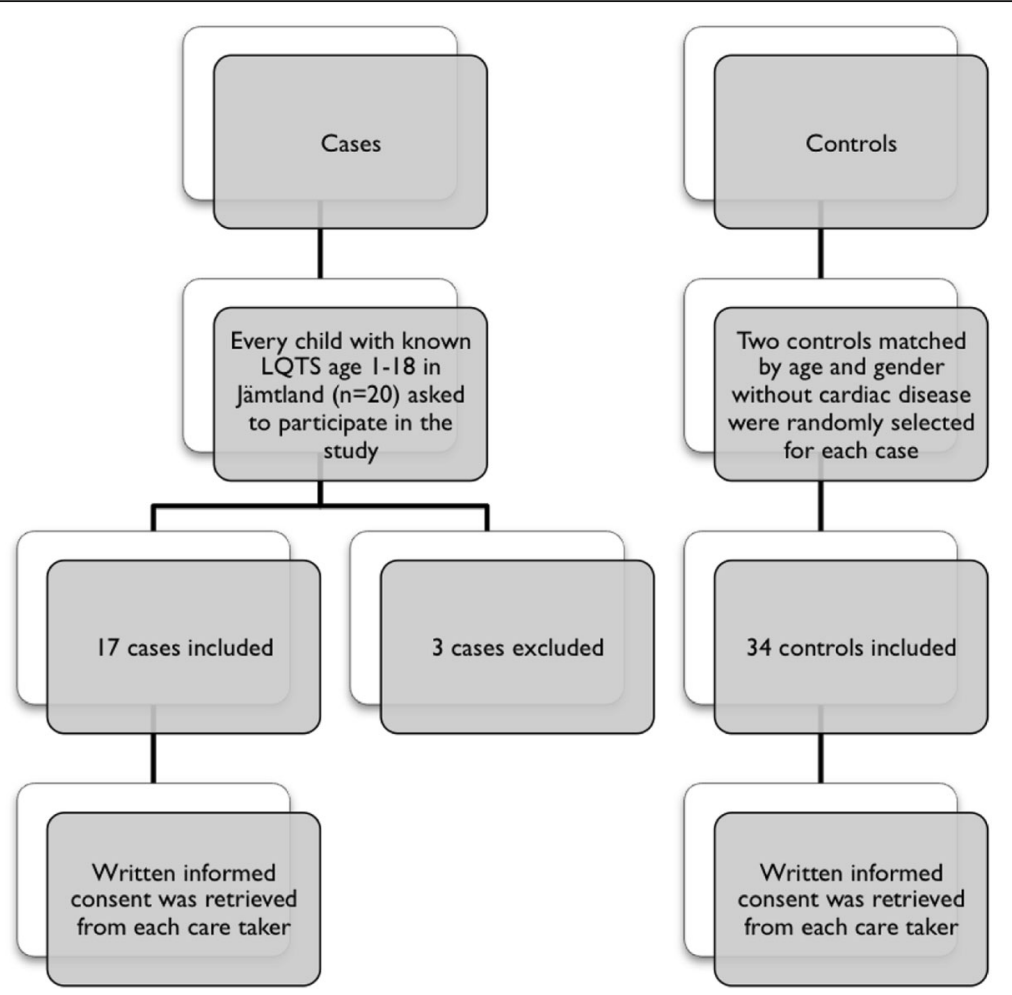

Fig. 1 Study population

Table 1 Population characteristics - demographics

\begin{tabular}{|c|c|c|c|}
\hline Variables & Cases $N=17$ & Controls $N=34$ & $p$ \\
\hline Weight mean $(\mathrm{kg})$ & 35.0 (SD 22.3) & 38.8 (SD 20.8) & 0.552 \\
\hline Height mean (cm) & $134.2(S D 24.9)$ & $136.6(S D 24.4)$ & 0.745 \\
\hline Female n (\%) & $9 / 17(53 \%)$ & 18/34 (53\%) & 1.00 \\
\hline Male n (\%) & $8 / 17(47 \%)$ & $16 / 34(47 \%)$ & 1.00 \\
\hline Age mean (years) & 9.0 (SD 4.2) & 9,4 (SD 4.2) & 0.724 \\
\hline Beta-blocker therapy n (\%) & 17/17 (100\%) & 0/34 (0\%) & $<0.001$ \\
\hline Systolic BP mean (mm Hg) & 100.7 (SD 8.3) & 109.1 (SD 13.3) & 0.021 \\
\hline Diastolic BP mean $(\mathrm{mm} \mathrm{Hg})$ & $56.0(S D 10.5)$ & 69.8 (SD 12.2) & $<0.001$ \\
\hline Medications on LQTS avoid list n (\%) & $4 / 17(23.5 \%)$ & $3 / 34(8.8 \%)$ & 0.203 \\
\hline Other medications n (\%) & $4 / 17(23.5 \%)$ & 16/34 (47.0\%) & 0.135 \\
\hline Occasional medications n (\%) & $3 / 17(17.6 \%)$ & $12 / 34(35.2 \%)$ & 0.328 \\
\hline Heredity for LQTS n (\%) & $17 / 17(100 \%)$ & 0/34 (0\%) & $<0.001$ \\
\hline History of syncope n (\%) & $1 / 17(5.8 \%)$ & $2 / 34(5.8 \%)$ & 1.00 \\
\hline Asthma n (\%) & $6 / 17(35 \%)$ & $6 / 34(17 \%)$ & 0.181 \\
\hline Diabetes n (\%) & 0/17 (0\%) & $5 / 34(14.7 \%)$ & 0.156 \\
\hline Other diseases n (\%) & $3 / 17(17.6 \%)$ & 9/34 (26.4\%) & 0.728 \\
\hline
\end{tabular}


Table 2 QTC compared between groups

\begin{tabular}{|c|c|c|c|c|}
\hline QTc between groups & Case group $(N=17)$ & Control group $(N=34)$ & Difference & $p$ \\
\hline QTc in supine position mean (ms) & 423.7 (SD 27.4) & $391.4(S D 22.4)$ & 32.3 & $<0.001$ \\
\hline QTc in standing position mean (ms) & 443.5 (SD 39.5) & 403.3 (SD 21.3) & 40.2 & $<0.001$ \\
\hline QTc change mean (ms) & 19.7 (SD 24.5) & 11.9 (SD 26.7) & 7.8 & 0.308 \\
\hline QTc > $440 \mathrm{~m}$ in supine position $\mathrm{n}(\%)$ & $4 / 17(23.6 \%)$ & $0 / 34(0 \%)$ & 4 & 0.003 \\
\hline QTc $>440 \mathrm{~m}$ in standing position $\mathrm{n}(\%)$ & $8 / 17(47.0 \%)$ & $0 / 34(0 \%)$ & 8 & $<0.001$ \\
\hline
\end{tabular}

Ms milliseconds, SD Standard deviation

The mean QTc interval in the supine position was longer for cases (423.7 ms) compared to controls $(391.4 \mathrm{~ms})$ $(p<0.001)$ (Table 2, Figs. 2 and 3). The QTc interval was longer for cases $(443.5 \mathrm{~ms})$ compared to controls $(403.3 \mathrm{~ms})(p<0.001)$ while standing (Table 2, Figs. 2 and 3), with a significant increase (Table 3). There was no difference in QTc-interval change between cases and controls in the supine position compared with standing $(p=0.308)$ (Table 2). A QTc interval of over $440 \mathrm{~ms}$ was calculated in four (24\%) at the supine position and in eight (47\%) while standing, but not in any of the controls $(p=0.003)$ (Table 2).

\section{Standing test}

The standing test was able to identify LQTS at risk by ECG and reached a specificity of $100 \%$ and a sensitivity of $47.0 \%$. The ability to identify a patient with LQTS on ECG while lying down reached a specificity of $100 \%$ and a sensitivity of $24 \%$ in our study.

\section{Discussion}

This pilot case-control study assessed the QTc interval in children with LQTS compared to healthy controls. An increased QTc-interval was present in children with LQTS in supine and standing body positions compared with controls. The standing test detected eight cases with prolonged QTc $>440 \mathrm{~ms}$, which was not observed in four of the children while in a supine position.

\section{Prolongation of QTc-interval in children and testing}

A prolongation of QTc-interval in healthy children when standing is in line with other studies [24, 26]. According to the national guidelines, a QTc interval over $440 \mathrm{~ms}$ may indicate a risk of LQTS [14]. A QTc $>440 \mathrm{~ms}$ was observed in a large proportion of healthy children in other studies, while none of the healthy controls in our study presented a QTc $>440 \mathrm{~ms}[24,26]$. The difference in the standing test method used in our study compared to other studies may explain the shorter QTc among

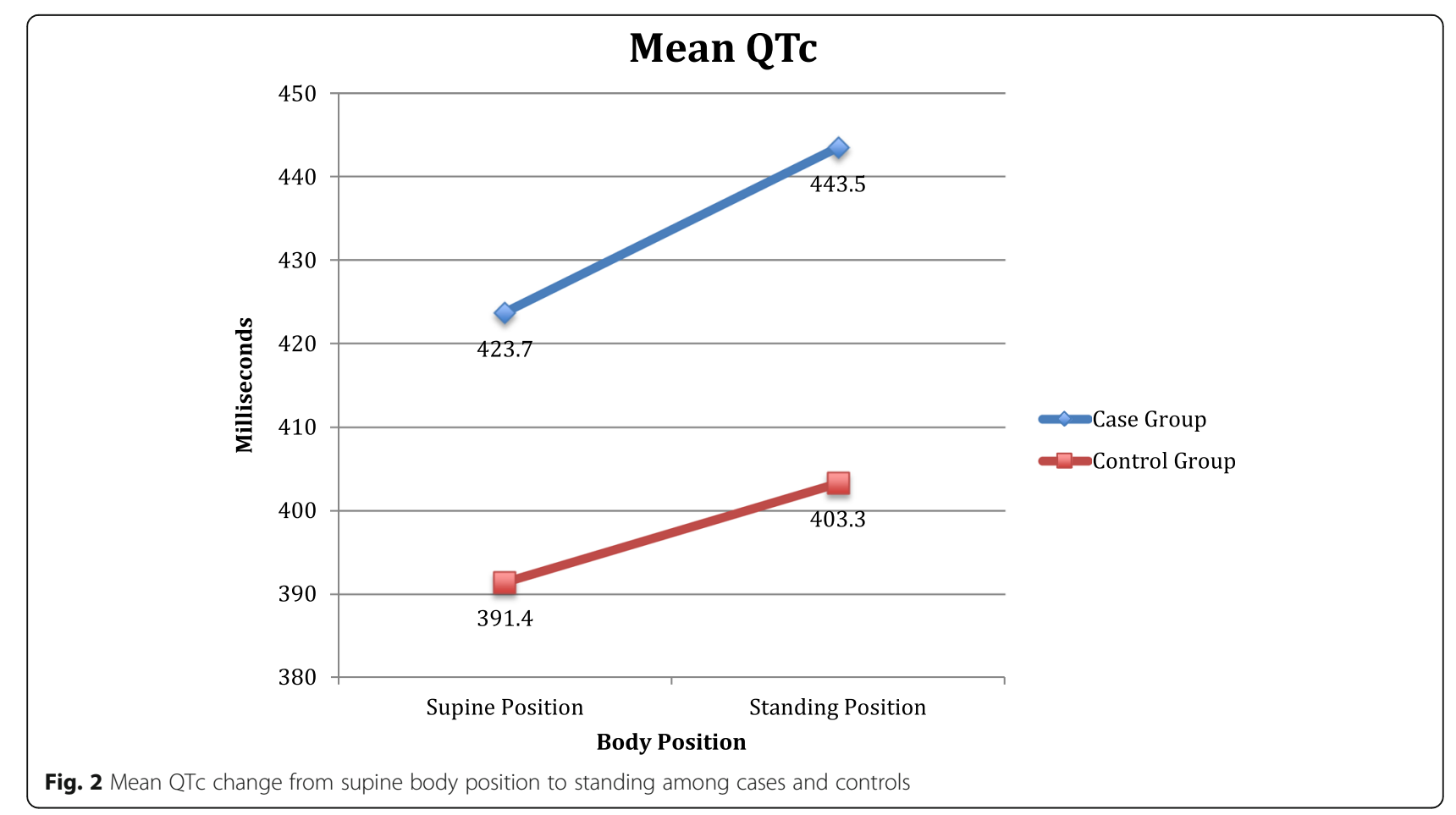




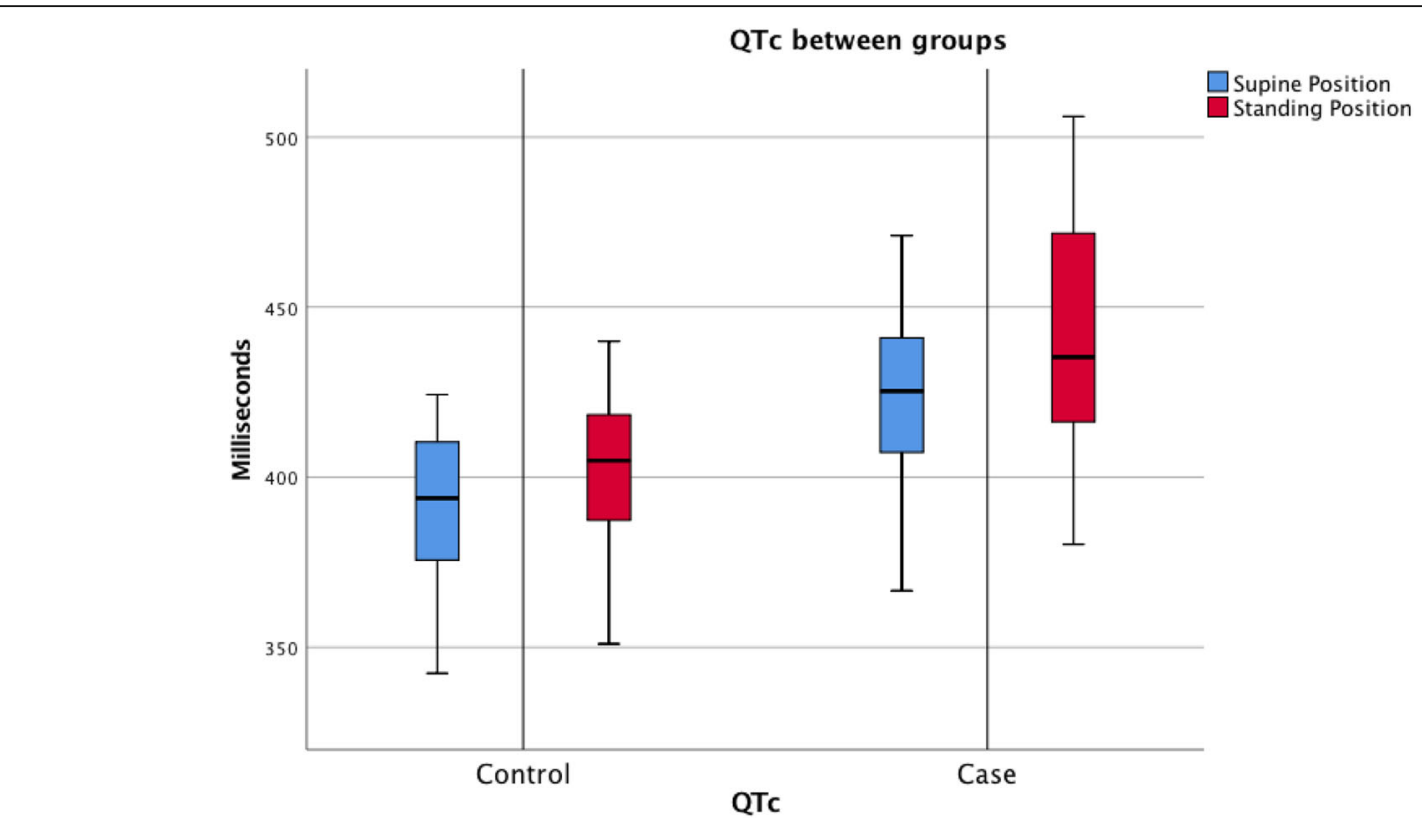

Fig. 3 QTc median, range and percentiles of QTc for cases and controls

controls in our study. The ECG standing was performed immediately after the ECG in the supine position, while others used a continuation of repeated ECG conducted at one-minute intervals $[24,26]$. We chose to use this simpler method to better mimic a clinical setting at the emergency department where a simple standing test can be used in patients admitted to the ward for syncope. The QTc interval changes in children are mainly dependent on the increased heart rhythm while standing [26]. One can speculate that the lack QTc increase in other studies in repeated ECG may have captured the maximum tachycardia level in healthy controls and LQTS patients with normal autonomic function, and QTc measurements in our study did not adjust the maximum heart rhythm [26].

Our study indicates that the standing test with a sensitivity of $100 \%$ may rule out the risk of misclassifying a healthy child with LQTS. However, the specificity was only $47 \%$, and a standing test will never be sufficient to confirm the diagnosis of LQTS. We believe that the standing test, together with other EST and 24-h ECG, may be used to evaluate which patients are likely to benefit from genetic screening. Furthermore, a standing test such as this is easy to perform and can be a useful tool in the selection of patients at risk.
Prolongation of QTc-interval in children; gender and age Increased mean resting heart beat and a longer QTc interval are observed among premenopausal females, indicating that age as well as gender and hormonal levels influence electrophysical processes and characteristics $[29,30]$. The standing test in adults provides diagnostic information as the QT interval increases in response to heart rate acceleration by standing [22]. Age has been correlated with postural heart rate, as a higher heart rate does not indicate an increase in orthostatic intolerance [31]. The study group in this study was young, predominantly in a prepubertal age group; $76 \%$ were under the age of 12 . Information on growth and development, including Tanner stage, is missing in our study, and the study group was too small for age-specific calculations. Further studies on standing tests during different levels of growth may be helpful in discriminating borderline LQTS patients from healthy pre- and pubertal children.

\section{Confounding factors, limitations and strength of the study}

Cases had a lower systolic and diastolic blood pressure compared to controls (Table 1). This discrepancy is likely due to the use of beta-blockers among cases [32]. It is possible that beta-blockers may mask some of the QTc prolongation among children with LQTS. A

Table 3 QTC compared within groups

\begin{tabular}{lllll}
\hline QTc change within groups & Supine position & Standing position & Difference & $p$ \\
\hline Case group mean (ms) & $423.7($ SD 27.4) & 443.5 (SD 39.5) & 19.7 & $\mathbf{0 . 0 0 4}$ \\
Control group mean (ms) & 391.4 (SD 22.4) & 403.3 (SD 21.3) & $\mathbf{1 1 . 9}$ & $\mathbf{0 . 0 1 4}$ \\
\hline
\end{tabular}

Ms milliseconds, SD Standard deviation

A significant change in QTc mean from supine to standing position for case- and control-group. 
majority of patients with LQTS are treated with betablockers, which is recommended by the national guidelines [14]. Thus, it would be unethical to test QTc in LQTS patients without medications.

The controls were randomly selected and attended the pediatric department for other medical conditions and matched by age, gender and absence of heart disease. Matching two controls for each case increased the sample size and power of the study. There is a risk for selection bias, as our controls were visiting the hospital for other medical conditions that may influence the risk of prolonged QTc by the condition itself or by medication. There was no difference between cases and controls regarding age, gender, weight or medication other than beta-blockers; thus, we believe the risk of selection bias influencing our results is limited.

\section{Conclusions}

This pilot study shows significant differences in the QTc interval between children with LQTS and healthy controls in both the supine and standing positions, with a significantly prolonged interval in children with LQTS. With a standing test, we were able to detect a prolonged QTC interval in four cases, which was not present in these children while in a supine body position. These results suggest that there are significant differences between children with LQTS and healthy controls and that the use of a standing test could be valuable for the evaluation of syncope when suspecting LQTS.

\section{Abbreviations}

ECG: Electrocardiogram; EST: Exercise testing; LQTS: Long QT syndrome; ms: Milliseconds

\section{Acknowledgments}

We would like to thank the children and parents included in this study and RN Mari Viktström-Gustafsson in the Pediatric Department in Östersund for help with ECG.

\section{Authors' contributions \\ EN had primary responsibility for the study, protocol development, patient enrollment and outcome assessment and for writing the manuscript. BR performed patient enrollment, taking ECG, final data analyses and contributed to the writing of the manuscript. GT contributed to protocol development, data analyses, outcome assessment and manuscript writing. All authors read and approved the final manuscript.}

\section{Funding}

Open access funding provided by Umea University.

\section{Availability of data and materials}

The data that support the findings of this study are available from the authors upon reasonable request.

\section{Ethics approval and consent to participate}

This study was approved by the Ethical committee for medical research at Umeå University, Medical faculty, Sweden,; Reference Number Dnr: 2018/ 158-31. Written consent from each parent was retrieved.

\section{Consent for publication}

Not applicable.

\section{Competing interests}

The authors declare that they have no competing interests.

Received: 16 October 2019 Accepted: 4 February 2020

Published online: 06 March 2020

\section{References}

1. Driscoll DJ, Jacobsen SJ, Porter CJ, Wollan PC. Syncope in children and adolescents. J Am Coll Cardiol. 1997;29(5):1039-45.

2. Singhi P, Saini AG. Syncope in pediatric practice. Indian J Pediatr. 2018;85(8): 636-40.

3. Anderson JB, Willis M, Lancaster $\mathrm{H}$, Leonard $\mathrm{K}$, Thomas $\mathrm{C}$. The evaluation and Management of Pediatric Syncope. Pediatr Neurol. 2016;55:6-13.

4. Moodley M. Clinical approach to syncope in children. Semin Pediatr Neurol. 2013;20(1):12-7.

5. Matsushima $\mathrm{R}$, Tanaka $\mathrm{H}$, Tamai $\mathrm{H}$. Comparison of the active standing test and head-up tilt test for diagnosis of syncope in childhood and adolescence. Clin Auton Res. 2004;14(6):376-84.

6. Alders M, Bikker H, Christiaans I. Long QT syndrome. In: Adam MP, Ardinger HH, Pagon RA, Wallace SE, Bean LJH, Stephens K, et al., editors. GeneReviews((R)). Seattle: University of Washington 1993.

7. Goldenberg I, Horr S, Moss AJ, Lopes CM, Barsheshet A, McNitt S, et al. Risk for life-threatening cardiac events in patients with genotype-confirmed long-QT syndrome and normal-range corrected QT intervals. J Am Coll Cardiol. 2011:57(1):51-9.

8. Ackerman MJ. Cardiac channelopathies: it's in the genes. Nat Med. 2004; 10(5):463-4

9. Schwartz PJ, Crotti L, Insolia R. Long-QT syndrome: from genetics to management. Circ Arrhythm Electrophysiol. 2012;5(4):868-77.

10. Shimizu W. Clinical impact of genetic studies in lethal inherited cardiac arrhythmias. Circ J. 2008;72(12):1926-36.

11. Aziz PF, Wieand TS, Ganley J, Henderson J, Patel AR, lyer VR, et al. Genotypeand mutation site-specific QT adaptation during exercise, recovery, and postural changes in children with long-QT syndrome. Circ Arrhythm Electrophysiol. 2011:4(6):867-73.

12. Bai R, Napolitano C, Bloise R, Monteforte N, Priori SG. Yield of genetic screening in inherited cardiac channelopathies: how to prioritize access to genetic testing. Circ Arrhythm Electrophysiol. 2009;2(1):6-15.

13. Priori SG, Napolitano C, Schwartz PJ. Low penetrance in the long-QT syndrome: clinical impact. Circulation. 1999;99(4):529-33.

14. Eliasson HJ, Nygren I, Rydberg A, Sjöborg A, Alpman M. National guidelines for mangement of LQTS. Kongenitalt långt QT syndrom LQTS Vårdprogram barn och ungdomar (Swedish): Swedish Pediatric Cardiology Society; 2016. https://sbkf.barnlakarforeningen.se/wp-content/uploads/sites/17/2017/02/ VP_LQTS-161129-final.pdf.

15. Taggart NW, Haglund CM, Tester DJ, Ackerman MJ. Diagnostic miscues in congenital long-QT syndrome. Circulation. 2007;115(20):2613-20.

16. Colman N, Bakker A, Linzer M, Reitsma JB, Wieling W, Wilde AA. Value of history-taking in syncope patients: in whom to suspect long QT syndrome? Europace. 2009;11(7):937-43.

17. Berger $\mathrm{S}$, Maccalli E. Strategies for the prevention of sudden cardiac death in children and adolescents. Pediatr Ann. 2015;44(12):e292-7.

18. Horner JM, Horner MM, Ackerman MJ. The diagnostic utility of recovery phase QTc during treadmill exercise stress testing in the evaluation of long QT syndrome. Heart Rhythm. 2011;8(11):1698-704.

19. Johnson ER, Etheridge SP, Minich LL, Bardsley T, Heywood M, Menon SC. Practice variation and resource use in the evaluation of pediatric vasovagal syncope: are pediatric cardiologists over-testing? Pediatr Cardiol. 2014;35(5): 753-8.

20. Vuksanovic V, Gal V, Kalanj J, Simeunovic S. Effect of posture on heart rate variability spectral measures in children and young adults with heart disease. Int J Cardiol. 2005;101(2):273-8.

21. Lipsitz LA, Mietus J, Moody GB, Goldberger AL. Spectral characteristics of heart rate variability before and during postural tilt. Relations to aging and risk of syncope. Circulation. 1990;81(6):1803-10.

22. Viskin S, Postema PG, Bhuiyan ZA, Rosso R, Kalman JM, Vohra JK, et al. The response of the QT interval to the brief tachycardia provoked by standing: a bedside test for diagnosing long QT syndrome. J Am Coll Cardiol. 2010; 55(18):1955-61.

23. Adler A, van der Werf C, Postema PG, Rosso R, Bhuiyan ZA, Kalman JM, et al. The phenomenon of "QT stunning": the abnormal QT prolongation 
provoked by standing persists even as the heart rate returns to normal in patients with long QT syndrome. Heart Rhythm. 2012;9(6):901-8.

24. Dionne A, Fournier A, Dahdah N, Abrams D, Khairy P, Abadir S. Dynamic QT interval changes from supine to standing in healthy children. Can J Cardiol. 2018;34(1):66-72.

25. Johnson JN, Ackerman MJ. QTc: how long is too long? Br J Sports Med. 2009;43(9):657-62.

26. Filippini L, Postema PG, Zoubin K, Hermans BJM, Blom NA, Delhaas T, et al. The brisk-standing-test for long QT syndrome in prepubertal school children: defining normal. Europace. 2018;20(F11):f108-f12.

27. Postema PG, Wilde AA. The measurement of the OT interval. Curr Cardiol Rev. 2014;10(3):287-94.

28. Bazett H. An analysis of the time-relations of electrocardiograms. Ann Noninvasive Electrocardiol. 1997;2(2):177-94.

29. Linde C, Bongiorni MG, Birgersdotter-Green U, Curtis AB, Deisenhofer I, Furokawa T, et al. Sex differences in cardiac arrhythmia: a consensus document of the European Heart Rhythm Association, endorsed by the Heart Rhythm Society and Asia Pacific Heart Rhythm Society. Europace. 2018;20(10):1565-1565ao.

30. Linde C, Cleland JGF, Gold MR, Claude Daubert J, Tang ASL, Young JB, et al. The interaction of sex, height, and QRS duration on the effects of cardiac resynchronization therapy on morbidity and mortality: an individual-patient data meta-analysis. Eur J Heart Fail. 2018;20(4):780-91.

31. Ives $C T$, Kimpinski K. Higher postural heart rate increments on head-up tilt correlate with younger age but not orthostatic symptoms. J Appl Physiol (1985). 2013:115(4):525-8

32. Cockburn JA, Brett SE, Guilcher A, Ferro A, Ritter JM, Chowienczyk PJ. Differential effects of beta-adrenoreceptor antagonists on central and peripheral blood pressure at rest and during exercise. $\mathrm{Br} J \mathrm{Clin}$ Pharmacol. 2010;69(4):329-35.

\section{Publisher's Note}

Springer Nature remains neutral with regard to jurisdictional claims in published maps and institutional affiliations.

Ready to submit your research? Choose BMC and benefit from:

- fast, convenient online submission

- thorough peer review by experienced researchers in your field

- rapid publication on acceptance

- support for research data, including large and complex data types

- gold Open Access which fosters wider collaboration and increased citations

- maximum visibility for your research: over $100 \mathrm{M}$ website views per year

At $\mathrm{BMC}$, research is always in progress.

Learn more biomedcentral.com/submissions 